\title{
Avances sobre la dinámica de la fermentación y su efecto en la calidad del pisco
}

Progress on the dynamics of fermentation and its effect on the quality of pisco

Recibido: marzo de 2016 | Revisado: abril e 2016 | Aceptado: mayo de 2016

Ana Hurtado Alendes ${ }^{1}$

Silvia Ara Rojas ${ }^{2}$

Fernando RAmos EsCUdero ${ }^{3}$

Edy Barnett Mendoza ${ }^{4}$

Luis López PALOMino ${ }^{5}$

Luis Celi SAAVedra ${ }^{6}$
Facultad de Ingeniería y Arquitectura de a Universidad de San Martín de Pores

1 ahurtadoa@usmp.pe

2 sarar@usmp.pe

3 diomedes.fernando@gmail. com

4 ebarnttm@usmp.pe

5 lpalominol@usmp.pe

6 lcelis@usmp.pe

\begin{abstract}
Molds, bacteria and indigenous yeasts were isolated during a spontaneous fermentation of grape from the Italy variety, all from the valley of Lima. Monitoring of the fermentation was performed by determining the density, temperature, soluble solids ( ${ }^{\circ}$ Brix), $\mathrm{pH}$ and ethanol content. At the same time it was performed a cell count of bacteria, molds and yeasts in R2A and Sabouraud agar plates, as well as a biochemical analysis of the wort. During spontaneous fermentation we isolated five strains of bacteria, three strains of molds and seven from yeast. During the early phases of spontaneous fermentation, yeasts of Hanseniaspora gender were the majority, but from the eighth day of fermentation the specie $S$. cerevisiae achieved the top, and its strain was isolated to the end of fermentation. Biochemical analyzes showed that flavanols increased until the seventh day of fermentation, decreasing by $10 \%$ until its end. For the biochemical identification of yeast strains of S.cerevisiae species, the identification kit RapID Yeast Plus System (Remel) will be used in order to establish their carbon sources usage profiles
\end{abstract}

Key words: autochtonous yeast, spontaneous fermentation, biochemical analysis.

\section{RESUMEN}

Se aislaron bacterias mohos y levaduras autóctonas durante una fermentación espontánea de mosto de uva de la variedad italia, procedente del valle de Lima. El seguimiento de la fermentación se realizó determinando la densidad, temperatura, sólidos solubles ( $\left.{ }^{\circ} \mathrm{Brix}\right), \mathrm{pH}$ y el porcentaje de etanol. Durante la misma se realizó el recuento de células de bacterias, mohos y levaduras en placas con agar R2A y Sabouraud, así como el análisis bioquímico del mosto. Durante la fermentación espontánea se aislaron cinco cepas de bacterias, tres de mohos y siete de levaduras. Durante las primeras fases de la fermentación espontánea, las levaduras del género Hanseniaspora fueron las mayoritarias, pero a partir del octavo día de fermentación se impuso totalmente la especie S.cerevisiae, siendo una cepa de esta especie la que fue aislada hasta el final de la fermentación. Los análisis bioquímicos mostraron que los flavanoles aumentaron hasta el séptimo día de la fermentación disminuyendo en un $10 \%$ hasta el final de la misma. Para la identificación bioquímica de las cepas de levaduras de la especie S.cerevisiae se utilizará el kit de identificación RapID Yeast Plus System (Remel) a fin de establecer sus perfiles de utilización de fuentes de carbono.

Palabras clave: levaduras autóctonas, fermentación espontánea, análisis bioquímico. 


\section{Introducción}

El pisco es uno de nuestros productos bandera obtenido por destilación del vino de una gran variedad de uvas denominadas pisqueras y de producción en diferentes valles de la costa peruana. En el contexto de la producción de bebidas alcohólicas destiladas, es considerado y valorado como una bebida de alta calidad por la materia prima utilizada y tecnología utilizada en su producción. Su consumo se ha incrementado en los últimos años, tanto en el mercado local así como en términos de su exportación a países desarrollados (Cacho, Moncayo, Palma, Ferreira \& Culleré, 2013).

A nivel mundial, se le considera como un aguardiente único debido a ventajas comparativas que presenta nuestra producción de uvas pisqueras referidas a consideraciones del componente suelo-clima, y a la tecnología utilizada en su producción. El sabor y el aroma peculiar del pisco se deben a los factores antes mencionados y a la presencia de algunos componentes formados durante el proceso de fermentación y destilación (Palma, 2011).

El presidente de la Comisión Nacional del Pisco (CONAPISCO), Sr. Carlos Carrillo Mora, señala que en el 2015, la producción del pisco alcanzó la cifra récord de producción de 9.5 millones de litros, indicando además que el crecimiento acumulado de la producción de pisco entre el 2011 y el 2015 fue de $34 \%$. Según esta misma fuente, la producción de los dos últimos años ha sido positiva debido al impulso que ha tenido el pisco, a las campañas realizadas y al ingreso a nuevos mercados (Ministerio de la producción, 2016).

Es importante señalar que el posicionamiento de nuestra bebida bandera se viene dando por la investigación e innovación tecnológica que está llevando a cabo el sector empresarial, el CITE VID y universidades como es el caso de la nuestra, que se traduce en el hecho de que el año 2000 había solo 48 certificaciones de Denominación de Origen Pisco, mientras que para el año 2014 estas han superado las 700, lo cual representa un crecimiento de 1,300\%. Asimismo, el presidente de CONAPISCO menciona que en ese mismo lapso, las marcas registradas de pisco dieron el salto de 16 a más de 400 , creciendo en $2400 \%$, indicando además que en la actualidad operan en nuestro país 453 empresas productoras de pisco y es Lima la región que concentra la mayor cantidad de empresas (44.4\%), seguida de Ica (38.4\%).

El pisco peruano se obtiene de diferentes variedades de uva, dentro de las cuales se pueden distinguir el grupo de las uvas aromáticas como la italia, albilla, moscatel y torontel y el grupo de las uvas no-aromática como la quebranta, negra criolla, mollar y uvina. Las variedades más representativas para la elaboración del pisco peruano son la italia y quebranta; además la uva italia es una de las variedades aromáticas con más alta producción en este sector (Huertas, 2004).

Es necesario remarcar que la calidad del pisco está determinada, principalmente, por el proceso de fermentación a que es sometido el jugo de uva. Sin embargo, se ha realizado un reducido número de investigaciones sobre este proceso por parte de Centros de Investigación y universidades. La calidad de un producto de fermentación depende, en gran medida, de las especies de microrganismos participantes que se encuentran, generalmente, en la superficie de las uvas, siendo ellas las responsables (de acuerdo a su tipo de metabolismo) de los compuestos químicos que constituyen el producto final y, por lo tanto, de calidades organolépticas como sabor, olor, color, entre otras (Raspor, Milek, Polanc, Mozina \& Cadez, 2006).

Algunos trabajos previos han coincidido en que las levaduras apiculadas son las especies predominantes sobre las superficies 
de los granos de uva, Hanseniaspora uvarum (y su forma anamorfa Kloeckera apiculatum) representó entre el 50-75\% de la población total de levaduras aisladas, aunque en menor población se han encontrado presentes especies de las levaduras de los géneros Candida, Cryptoccocus, Hansenula, Kluyveromyces, Metschnikowia, Pichia y Rhodotorula. Contrariamente a lo que se pensaba, las especies fermentativas de Sacharomyces se han aislado, en muy baja población, sobre uvas sanas y han sido extrañamente aisladas de uvas intactas y de suelos de viñedos. Se ha comprobado que estas especies fermentativas están asociadas con el área de la bodega y que son incorporadas dentro del mosto durante el tratamiento mecánico de la uva y el proceso de fermentación (Barrajón, Arévalo-Villena, Rodríguez-Aragón \& Briones, 2009; Beltrán et al., 2002; Naumov, Naumova \& Gaillardin, 1993; Raspor et al., 2006; Sabate, Cano, Esteve-Zarzoso \& Guillamón, 2002; Sun, Ma, Hao, Pretorius \& Chen, 2009).

Todas las levaduras que se incorporan al mosto provenientes de la superficie de las uvas no son capaces de soportar las condiciones de vinificación Así, las levaduras no-Saccharomyces crecen bien durante las primeras etapas de fermentación, cuando la concentración de etanol es aún baja, pero más tarde, estas son reemplazadas por cepas de la especie S.cerevisiae que muestran una mejor adaptación a las condiciones de vinificación, por ser más tolerantes al etanol y más competitivas para crecer en un medio con alta concentración de azúcares (Sabate et al., 2002).

La relación entre levaduras no-Saccharomyces/Saccharomyces, al principio de la fermentación puede contribuir a acentuar los cambios tanto químicos como sensoriales, que en parte son debidos al hecho de que las levaduras no-Saccharomyces secretan una serie de enzimas (estereasas, glicosidasas, lipasas, $\beta$-glucosidasas, proteasas, celulasas, entre otras) que pueden interaccionar con los sustratos presentes en el medio mejorando algunas etapas del proceso de fermentación (Carrascosa, Muñoz \& González, 2005).

Si bien se conocen los géneros y, en algunos casos, las especies de levaduras que suelen estar presentes en procesos de fermentación espontánea de mosto, no se conoce bien qué cepas de levadura son las que inician la fermentación del mismo, la procedencia ni el momento en que hace su aparición la levadura Saccharomyces cerevisiae (principal especie de levaduras fermentadoras) a lo largo de todo el proceso fermentativo ni el aporte de cada una de estas especies sobre el producto final.

Las Escuelas Profesionales de Ingeniería Industrial e Industrias Alimentarias de la Facultad de Ingeniería y Arquitectura de la Universidad de San Martín de Porres en el marco de su política de proyección a la comunidad vienen realizando investigaciones con la finalidad de colaborar con los productores de pisco, dentro de las cuales se han logrado importantes aportes como es el caso del diseño y construcción de "Prototipo de Destilador con Automatización Digital del Control de Variables en el Proceso de Destilación del Pisco-2004"; asimismo, el diseño y construcción de determinado grado alcohólico en línea con el proceso de destilación del pisco-2008, prototipos con patentes registrados en INDECOPI. La situación expuesta y la producción de pisco a nivel de planta piloto en nuestras instalaciones nos ha permitido obtener el registro sanitario y denominación de origen para la marca "San Martín" que nos alienta a continuar con los estudios para profundizar en el conocimiento de uno de los procesos de la producción de pisco como es la fermentación, en donde los microrganismos juegan un papel importante tema, objeto del estudio.

El presente trabajo permitió conocer el aporte de cada microorganismo (levadura) en el proceso fermentativo para la produc- 
ción del pisco en cuanto a composición química y características organolépticas deseables en el producto final, originando de este modo un tipo de pisco característico de cada producción. Asimismo, admitió proponer metodologías para el estudio de la dinámica poblacional de las levaduras que intervienen en la fermentación del mosto para la producción de pisco que permita generar información básica en busca de mejorar el proceso productivo y así producir pisco de alta calidad.

\section{Materiales y Métodos}

\section{Reactivos químicos y disoluciones}

Ácido gálico, catequina, carbonato de sodio, reactivo de Folin-Ciocalteu, 4-dimetilamino cinamaldehído, de Sigama-Aldrich (Steinheim, Alemania) y etanol, metanol, y ácido clorhídrico de Merck KGaA (Darmstadt, Alemania). Todos los reactivos fueron de grado analítico.

\section{Aislamiento y recuento de microorganis- mos presentes en los procesos}

Se realizó siguiendo el método horizontal para recuento de levaduras basadas en la norma ISO 7974, utilizando como medio de aislamiento Agar Sabouroud con $4 \%$ de glucosa (ASG), y el método horizontal para recuento de bacterias basadas en la norma ISO 4833 con R2A como medio de aislamiento. En los medios de cultivo, se sembraron por duplicado alícuotas del mosto puro y en dilución (10-1 a 10-4), dependiendo de la etapa de la fermentación. Las placas inoculadas fueron incubadas a $25^{\circ} \mathrm{C}$ por 48 a 72 horas para luego realizar los recuentos, reportándose como UFC/mL.

Las colonias de levaduras, desarrolladas en ASG, fueron examinadas macro y microscópicamente, procediéndose al re-aislamiento en ASG de todas las levaduras que presentasen alguna diferencia entre ellas (por ejemplo: tamaño, forma y color de colonias, forma, tipo de agrupación y tamaño de las células, etc.). Estos aislamientos se sembraron en tubos con MEA y ASG. Los cultivos en MEA (en agar recto) se cubrieron con vaselina estéril y se conservaron a $4^{\circ} \mathrm{C}$. Los cultivos en ASG serán utilizados para la caracterización fisiológica de los aislamientos mediante el kit RapID Yeast Plus System (Remel).

\section{Determinación del contenido de flavanoles}

El contenido de flavanoles se estimó utilizando 4-(dimetilamino) cinamaldehído, descrito por Arnous, Makris y Kefalas (2001). Se utilizó (+)- catequina como patrón de referencia en las siguientes concentraciones: 1, 2, 4, 8, 12, y 16 mg/L. La reacción se desarrolló usando $200 \mu \mathrm{l}$ de muestra $(100 \mu \mathrm{g} / \mathrm{mL})$ o estándar y $1 \mathrm{~mL}$ de solución de 4-(dimetilamino) cinamaldehído $(0.1 \%$ en metanol acidificado con $\mathrm{HCl} 1 \mathrm{~N})$. La mezcla se agitó fuertemente durante $10 \mathrm{mi}$ nutos, y la absorbancia se leyó a $640 \mathrm{~nm}$. La concentración de flavanoles totales se estimó a partir de una curva de calibrado, construida por el ploteo de las soluciones conocidas de la catequina $(1-16 \mathrm{mg} / \mathrm{mL})$ frente a las absorbancias recolectadas a A640 nm $\left(\mathrm{r}^{2}=\right.$ 0.9992). Los resultados se expresaron como $\mathrm{mg} / \mathrm{L}$ de equivalentes de catequina.

\section{Análisis estadístico}

Los datos analíticos (por triplicado) se analizaron mediante análisis de varianza unidireccional, seguido de la prueba de rango múltiple de Duncan al nivel de confianza del 95\% $(\mathrm{p}<0.05)$ utilizando un paquete estadístico (StatSoft, Tulsa, Oklahoma).

\section{Resultados}

\section{Aislamiento y recuento de microorganismo}

Como puede observarse en las Figuras 1,2 y 3 , respectivamente, la dinámica po- 
blacional observada durante los procesos de fermentación natural de mosto de uva de la variedad italia se caracterizó por poblaciones iniciales de $10^{5} \mathrm{UFC} / \mathrm{mL}$ de mohos, $10^{8}$ $\mathrm{UFC} / \mathrm{mL}$ de bacterias y $10^{7} \mathrm{UFC} / \mathrm{mL}$ de levaduras. Iniciada la fermentación, los recuentos de mohos y bacterias empezaron a disminuir a partir del segundo día, para luego desaparecer a partir del cuarto día.

En cambio, con las levaduras la población evidenció un crecimiento exponencial a partir del tercer día hasta alcanzar un máximo de $10^{11} \mathrm{UFC} / \mathrm{mL}$ para el quinto día de fermentación, manteniéndose estos valores hasta el día séptimo en que se inició un descenso prolongado que se mantuvo hasta el décimo día en que se paró la fermentación.

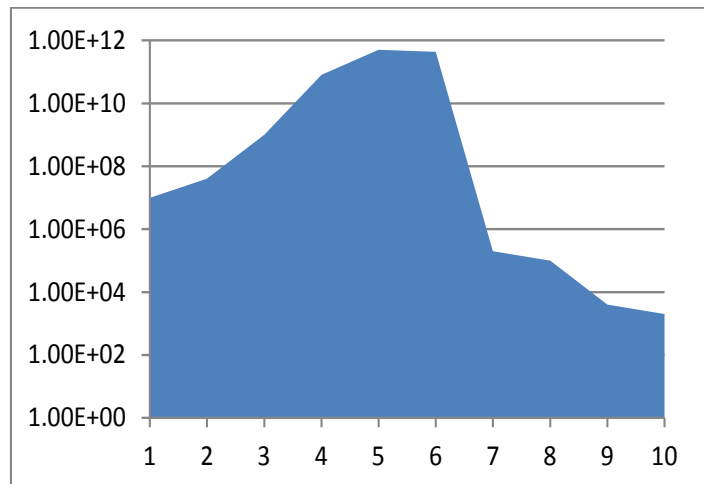

Figura 1. Dinámica poblacional de levaduras durante fermentación natural de mosto de uva variedad italia

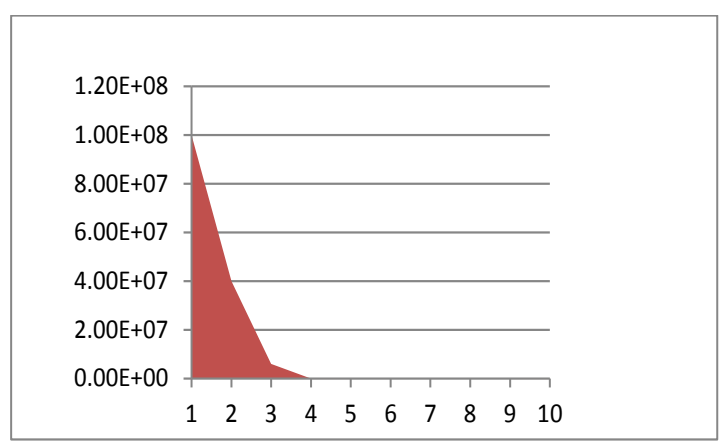

Figura 2. Dinámica poblacional de bacterias durante fermentación natural de mosto de uva variedad italia

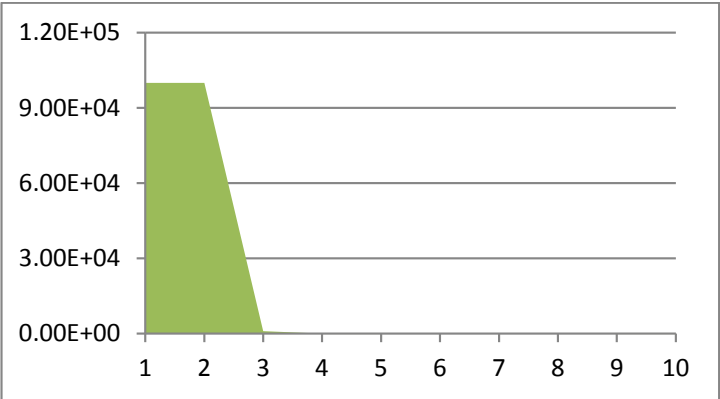

Figura 3. Dinámica poblacional de mohos durante fermentación natural de mosto de uva variedad italia

\section{Análisis de flavanoles}

Las frutas y verduras contienen muchos compuestos antioxidantes, incluyendo compuestos fenólicos, antocianinas y carotenoides, tocoferoles (Naczk \& Shahidi, 2006). Los polifenoles desempeñan un papel importante en la calidad de los alimentos, ya que están relacionados con el color, amargor y astringencia (Alonso-Salces et al., 2004). Ellos pueden estar involucrados en el proceso de fermentación y la producción de aromas, además de ser inhibidores del desarrollo de microorganismos.

Los resultados para la determinación de flavanoles totales se presentan en la Figura 4. El contenido de flavanoles totales varió de 4 a $102 \mathrm{mg}$ de catequina equivalente/L. Los resultados mostrados indican que el contenido de flavanoles aumenta con el desarrollo de la fermentación. A partir del séptimo día, este contenido disminuye, aproximadamente, en $10 \%$ del contenido total. El incremento del contenido de flavanoles correlaciona con lo reportado por Đorđević, Šiler-Marinković y Dimitrijević-Branković (2010), quienes mencionan que debido a la fermentación, mejora la actividad antioxidante por el aumento de la liberación de los flavonoides de los alimentos de origen vegetal, la fermentación es un método útil para aumentar el suministro de antioxidantes naturales. El rompimiento de las células de los cereales inducida por la fermentación también pueden liberar y/o inducir la síntesis de diversos compuestos bioactivos. 


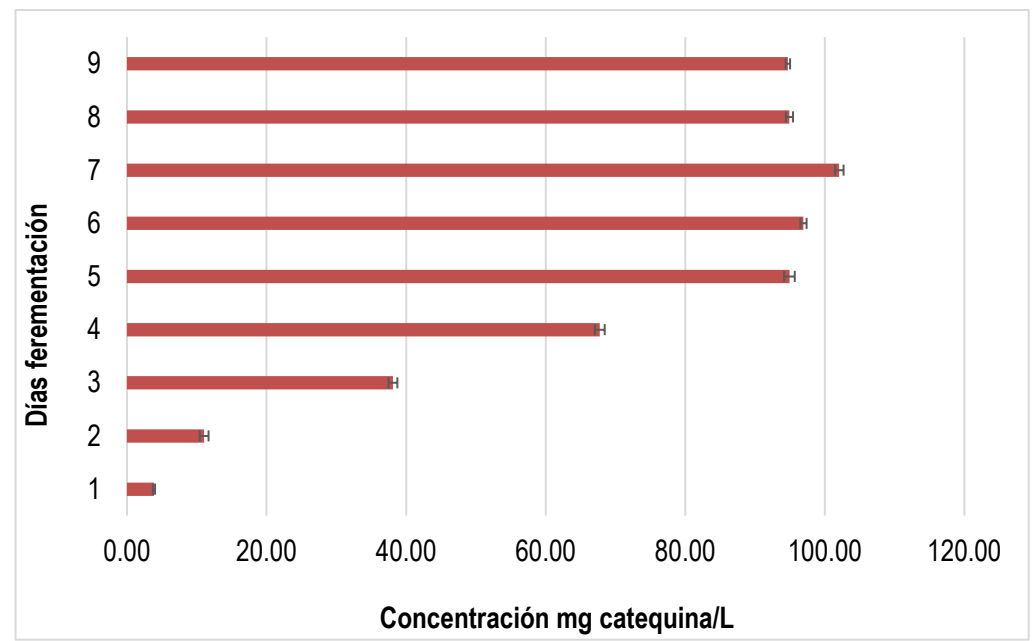

Figura 4. Efecto del tiempo de fermentación sobre el contenido de flavanoles total.

\section{Discusión}

Los resultados obtenidos sobre el recuento de microorganismos y el análisis de flavanoles durante la fermentación indican una correlación entre el recuento de levaduras y el contenido de flavanoles. Más estudios demostrarán si los flavanoles podrían comportarse como inhibidores de bacterias y mohos junto con el aumento del etanol durante el proceso de la fermentación.

Sería de mucha importancia conocer las cepas de levaduras que aparecen y desaparecen durante la fermentación para correlacionarlas con los componentes químicos identificados.

\section{Referencias}

Alonso-Salces, R. M., Barranco, A., Abad, B., Berrueta, L. A., Gallo, B. \& Vicente, F. (April, 2004). Polyphenolic profiles of Basque cider apple cultivars and their technological properties. Journal of Agricultural and Food Chemistry, 52(10), 2938-2952.

Arnous, A., Makris, D. P. \& Kefalas, P. (December, 2001). Effect of principal polyphenolic components in relation to antioxidant characteristics of aged red wines. Journal of Agricultural and Food Chemistry, 49(12), 5736-5742.

Barrajón, N., Arévalo-Villena, M., Rodríguez-Aragón, L. J. \& Briones, A. (2009). Ecological study of wine yeast in inoculated vats from La Mancha region. Food Control, 20(9), 778-783.
Beltrán, G., Torija, M. J., Novo, M., Ferrer, N., Poblet, M., Guillamón, J., ... Mas, A. (2002). Analysis of yeast population during alcoholic fermentation: A six year follow-up study. Systematic and Applied Microbiology, 25(2), 287-293.

Cacho, J., Moncayo, L., Palma, J. C., Ferreira, V. \& Culleré, L. (2013). The impact of grape variety on the aromatic chemical composition of non-aromatic Peruvian pisco. Food Research International, 54, 373-381.

Carrascosa, A., Muñoz R. \& González R. (2005). Microbiología del vino (1 ed.). España: AMV Ediciones.

Đorđević, T. M., Šiler-Marinković, S. S. \& Dimitrijević-Branković, S. I. (2010). 
Effect of fermentation on antioxidant properties of some cereals and pseudo cereals. Food Chemistry, 119(3), 957963.

Huertas, L. (2004). Historia de la producción de vinos y piscos en el Perú. Revista Universum, 19(2), 44-61.

Ministerio de la Producción (04 de febrero del 2015). El 2015 se registró cifra record de producción de pisco con 2.5 millones de litros. Recuperado de www.produce.gob.pe

Naczk, M. \& Shahidi, F. (August, 2006). Phenolics in cereals, fruits and vegetables: Occurrence, extraction and analysis. Journal of Pharmaceutical and Biomedical Analysis, 41(5), 15231542.

Naumov, G., Naumova, E. \& Gaillardin, C. (1993). Genetic and karyotypic identification of wine saccharomyces bayanus yeasts isolated in France and Italy. Systematic and Applied Microbiology, 16(2), 274-279.
Palma, J. C. (16 de febrero del 2011). Pisco: el aguardiente de uva de Perú [Mensaje en un blog]. Recuperado de http://agendaquimica.blogspot.com. es/2011/02/pisco-el-aguardiente-deuva-del-peru.html

Raspor, P., Milek, D. M., Polanc, J., Mozina, S. \& Cadez, N. (May, 2006). Yeasts isolated from three varieties of grapes cultivated in different locations of the Dolenjska vine-growing region, Slovenia. International Journal of Food Microbiology, 109(1-2), 97-102.

Sabate, J., Cano, J., Esteve-Zarzoso, B. \& Guillamón, J. M. (2002). Isolation and identification of yeasts associated with vineyard and winery by RFLP analysis of ribosomal yeast and mitochondrial ADN. Microbiological Research, 157(4), 267-274.

Sun, H., Ma, H., Hao, M., Pretorius, I. S. \& Chen, S. (2009). Identification of yeast population dynamics of spontaneous fermentation in Beijing wine region, China. Annals of Microbiology, 59(1), 69-76. 
